anmercifully in recounting his own list of honours, that he has neglected to mention the fact of Mr. Dale having passed his first examination for M.B. at the University of London, a distinction which, by the way, this man of many medals may look upon as unworthy of his consideration.

With this slight addition to the facts of the case, I think the "just and honourable reader" will have a much better opportunity of offering an "unbiassed and candid opinion" upon the subject.

That the "honour" conferred on Mr. Harris and Mr. Dale was not "merited," none but an anonymous correspondent would, I am sure, dare to deny; and I think we have no cause to regret that our hospital is represented by these gentlemen, rather than by one who can thus attempt to slander their fair fame, and yet has not the courage to avow himself openly in the cause of which he has given such a distorted representation.

By finding a place for the above in your forthcoming number you will oblige one who was, last year,

oct. 1853.

A London Hospital Student.

\section{CINNAMON IN MENORRHAGIA.} To the Editor of THE LANCET.

SIR,-On perusing your journal for the 15 th inst., T observed a communication from Dr. Tanner " On the Use of Cinnamon in certain Examples of Menorrhagia." After some prefatory observations as to the kind of disease in which he has found it efficacious, he goes on to remark that - "I am not aware that mention is made of it by gentlemen who have written on obstetrics and the diseases of women in this country." If Dr. Tanner will take the trouble to refer to Dr. Gooch's "Practical Compendium of Midwifery," he will find that that experienced physician and eminent writer was in the habit both of prescribing and recommending it in his lectures. In his article "Menorrhagia" will be found the following remarks :-

"On the Continent they use cinnamon as a tonic, and I have found it a good addition to the medicines of this kind which I usually prescribe. My common formula is a draught composed of fifteen drops of dilute sulphuric acid, one grain of sulphate of zinc, thirty drops of tincture of cinnamon, and one ounce of peppermint water, which is to be taken three times a day."

Although Dr. Gooch did not administer the remedy per se, still, however, it is evident that he considered the cinnamon an essential ingredient in the formula. I will only add that I have frequently prescribed the drug in question, according to the rules laid down by Dr. Gooch, and I believe with beneficial results.

I am, Sir, yours, \&c.,

Bolton-le-Moors, Laneashire, Oct. 1853. S. T. CHADWTCK.

\section{ON THE PREDISPOSITION TO CHOLERA.} To the Editor of THe LANCET.

SiR,--It appears to me that an important point connected with cholera has been ratheroverlooked-viz., the predisposition to the rece: tion of the disease. This has been forming among the people for years past, but has increased in degree very much within the last two or three years.

Cholera may be regarded as requiring three conditions for its development:--

1st. A predisposition forming during a series of years;

2ndly. An intensity given to this predisposition by local or incidental causes; and

3rdly. An exciting cause.

I believe, without the first, the second and third do not operate. I think the first condition has existed as a state of asthenia amongst the people for years past, as proved by the ill manner in which bleeding has been borne of late, compared with former years. By the existence of the plague of boils, and especially by the well-attested fact that much less mercury is now required to produce a given effect than formerly. It seems to be admitted, indeed, that asthenia is a general feature of almost all diseases that we have to treat. Ought we not, therefore, to direct our attention to the removal of this state, rather than wait for the sowing of the seed upon a soil so well adapted for its reception? It would seem probable, if this view be correct, that the administration of tonics, such as steel, daily and for weeks previous to the actual outbreak of the disease, might fortify the system to such a degree as to render it insusceptible of the poisonons impression. As to the exciting cause, unless you destroy the jungles of India, or convert its rivers into chloride of lime, you will probably never be able to deal therewith.

With great respect, I am, Sir, your obedient servant, Oct. 1853.

M.R.C.S.E,

\section{TH E C H OLER A.}

THE returns from the Board of Health show that the cholera can scarcely be called prevalent in any district. In Newcastle and Gateshead it seems to have entirely ceased, scarcely a single death having occurred in either place. In the Metropolis soli. tary cases are still reported from many districts; but as we observed in our report of last week, it is strongly asserted that many of these cases are not of the true Asiatic character. At all events there can be no doubt that if a case occurs from cholera of any description, there is in some quarters a disposition to number it amongst the "malignant" class. Cases have been reported from Dundee, Luton, Soham, (a village in the fens of Cambridgeshire, ) Cockermouth, Erdom, (Berwick,) Edinburgh, Farth-Carnwath, (Lanarkshire,) Portobello, Wolstanton, Tendrings, Easington Union, Thorne Union, Arbroath, South Shields, Ayton, (Berwick,) Chelmsford Union, Rye Union, St. George's-in-the-East, and St. James's, Piccadilly.

In none of these places, however, has the disease made any serious ravages; in almost all of them the daily deaths not exceeding one. The Board of Health have been pursuing their labours with much zeal in some districts, particularly those in the neighbourhood of the Metropolis, and their officers, Dr. G. Milroy and Mr. Hall, have in many instances urged upon the local authorities the necessity for the adoption of sanitary mea. sures. In those places in which cholera has as yet made its appearance, sufficient reason has been found for its presence in the dirty, ill-ventilated condition of the neighbourhood. As the reports, however, are at present furnished, no accurate data can be arrived at on some of the most important points in the inquiry. As yet even no facts have been given to show the contagiousness or non-contagiousness of the disease. Until a Government Commission is appointed to take the subject into consideration, no definite information can bearrived at.

SHoREDITCH AND ST. LuKE'S. - The defective and otherwise very faulty state of the sewerage in many parts is represented as a serious impediment in the way of sanitary improvement: with the view of giving greater efficiency to the labours of the local authorities in carrying out the regulations and directions of the General Board of Health, issued under the recent Order in Council, the boards of guardians in both parishes, after hearing the explanations given by Dr. Milroy, unanimously adopted the following resolutions:-

"That the medical officers be directed to act forthwith as sanitary inspectors, each in his own district, in pursuance of the directions of the Board of Health now in force.

"That this board will be ready hereafter to consider the extra remuneration of the medical officers, when the nature and amount of such extra services shall have been ascertained.

"That the clerk do forward a copy of this resolution to the medical officers severally."

The very responsible duties of active sanitary inspection, in conjunction with those of vigilant supervision of the health of the different districts, are thus devolved upon those who, by their local knowledge and their professional avocations, can most efficiently discharge them; thus making a first; but a most important step towards the formation of a health police.

\section{The Metropotis,}

Deaths from Cholera during the Deaths from Chotera in corre. period of 13 weeks, 1853.

Week ending :-

Aug. $6 \quad \ldots$

, 13

$" 20$

Sept. 3

, 10

," 17

," 24

oct. 1

, 8

,$\quad 15$

, 22

..

...

$\cdots$

...

...

...

..

...

...

...

..

...

...

...

$\cdots$

...

$\cdots$
$\cdots$
$\cdots$
$\cdots$

...

\begin{tabular}{r|} 
\\
4 \\
19 \\
10 \\
18 \\
16 \\
7 \\
16 \\
29 \\
48 \\
66 \\
45 \\
83 \\
96 \\
\hline 457
\end{tabular}
sponding period of 13 weeks in 1848.

Corresponding week, 184819

\begin{tabular}{|c|c|c|}
\hline , & " & ," \\
\hline ", & , & ", \\
\hline , & ", & ", \\
\hline , & $"$ & ", \\
\hline , & , & " \\
\hline ", & , & ", \\
\hline " & "צ & ", \\
\hline , & , & , \\
\hline , & $"$ & ", \\
\hline , & ", & $"$ \\
\hline ," & " & ", \\
\hline ", & ", & " \\
\hline
\end{tabular}

